\title{
Clinical Governance: Protecting the Health-Care Workers
}

\author{
Lakshmi Kumar, Keerthi Njerinjamkuzhi Satheesan', Meghalakshmi Alakkaparambil Ramachandran'1 \\ Department of Anaesthesiology and Critical Care, 'Department of Respiratory Therapy, Amrita Institute of Medical Sciences, Amrita Vishwa Vidyapeetham, Kochi, \\ Kerala, India
}

\section{Abstract}

Clinical governance in protecting the health-care worker $(\mathrm{HCW})$ refers to measures taken by the organization in providing a safe environment for the HCW while maintaining excellence in the quality of care for the patients. In the wake of the SARS-CoV-2 virus pandemic, the key regulatory measures are taken by the infection control authority of the hospital. The Donabedian model suggests that this process is considered as structure, process, and outcome review measures. Structural changes include surveillance, screening measures, creation of outpatient clinics for COVID-suspected patients, and separate isolated bay for collection of the nasopharyngeal swab. Structural processes also include the creation of separate intensive care units (ICUs) and theaters for infected patients, negative pressure gradient in the operating room (OR), and sites where aerosol generation could occur. Creation of operational pathways such as intubation in the ICU and in the OR should be included in this. The process involves training of HCWs at various levels on the use of personal protective equipment (PPE). Provision of adequate numbers of PPE and cleaning solutions and establishing the diagnostic pathways such as the antigen test, reverse transcriptase-polymerase chain reaction, or nucleic acid amplification test are part of the processes set up by any organization. Outcome analysis involves rates of HCW infection from COVID care wards and ICU, patients testing positive at screening, and patients who may test positive after they undergo treatment at the facility. Long-term outcome measure may include mortality and length of hospital stay.

Keywords: Clinical governance, health care workers, infection-control

\section{INTRODUCTION}

The rapidly spreading pandemic from SARS-CoV-2 virus has infected more than 102.3 million individuals worldwide and more than 2.2 million deaths have been reported as of February 2021. ${ }^{[1]}$ A new variant of SARS-CoV-2 virus has been reported by the Government of the United Kingdom to the World Health Organization (WHO) in December 2020 with spread documented to several countries including India. ${ }^{[2]}$

Clinical governance literally means an establishment of a frame work, wherein organizations are accountable for continually improving the quality of their services and safeguarding high standards of care by creating an environment, in which excellence in clinical care will flourish. Clinical governance in safety of the health-care worker (HCW) implies the establishment of protocols and guidelines with the provision of infrastructure that ensures maximal safety in the COVID context. The implementation of the Donabedian model has shown to improve outcomes at a hospital in New York. ${ }^{[3]}$

\begin{tabular}{|l|l|}
\hline \multicolumn{3}{|c|}{ Access this article online } \\
\hline Quick Response Code: & Website: \\
& www.ijrc.in \\
\hline
\end{tabular}

The institution should implement techniques for preventing the spread of infection in HCWs with the activation of Hospital Infection Control Committee (HICC). The Donabedian model and its application to an institution has been depicted in Figure 1 responsible for all the Infection control and Prevention activities as well as organizing training sessions for HCWs on safe infection control practices. ${ }^{[4]}$

The risks to the HCW based on their area of work are described in Table 1.

General measures to minimize spread of infection

1. "Break the Chain" campaign with the provision of soap and water at all entrances

Address for correspondence: Dr. Lakshmi Kumar, Department of Anaesthesiology and Critical Care, Amrita Institute of Medical Sciences, Kochi, Kerala, India. E-mail: lakshmi.k.238@gmail.com

This is an open access journal, and articles are distributed under the terms of the Creative Commons Attribution-NonCommercial-ShareAlike 4.0 License, which allows others to remix, tweak, and build upon the work non-commercially, as long as appropriate credit is given and the new creations are licensed under the identical terms.

For reprints contact: WKHLRPMedknow_reprints@wolterskluwer.com

How to cite this article: Kumar L, Satheesan KN, Ramachandran MA. Clinical governance: Protecting the health-care workers. Indian J Respir Care 2021;10:S8-14.

Received: $16-02-2021$

Published: 29-04-2021
Accepted: $17-02-2021$ 
Kumar, et al.: Protecting health care workers during COVID

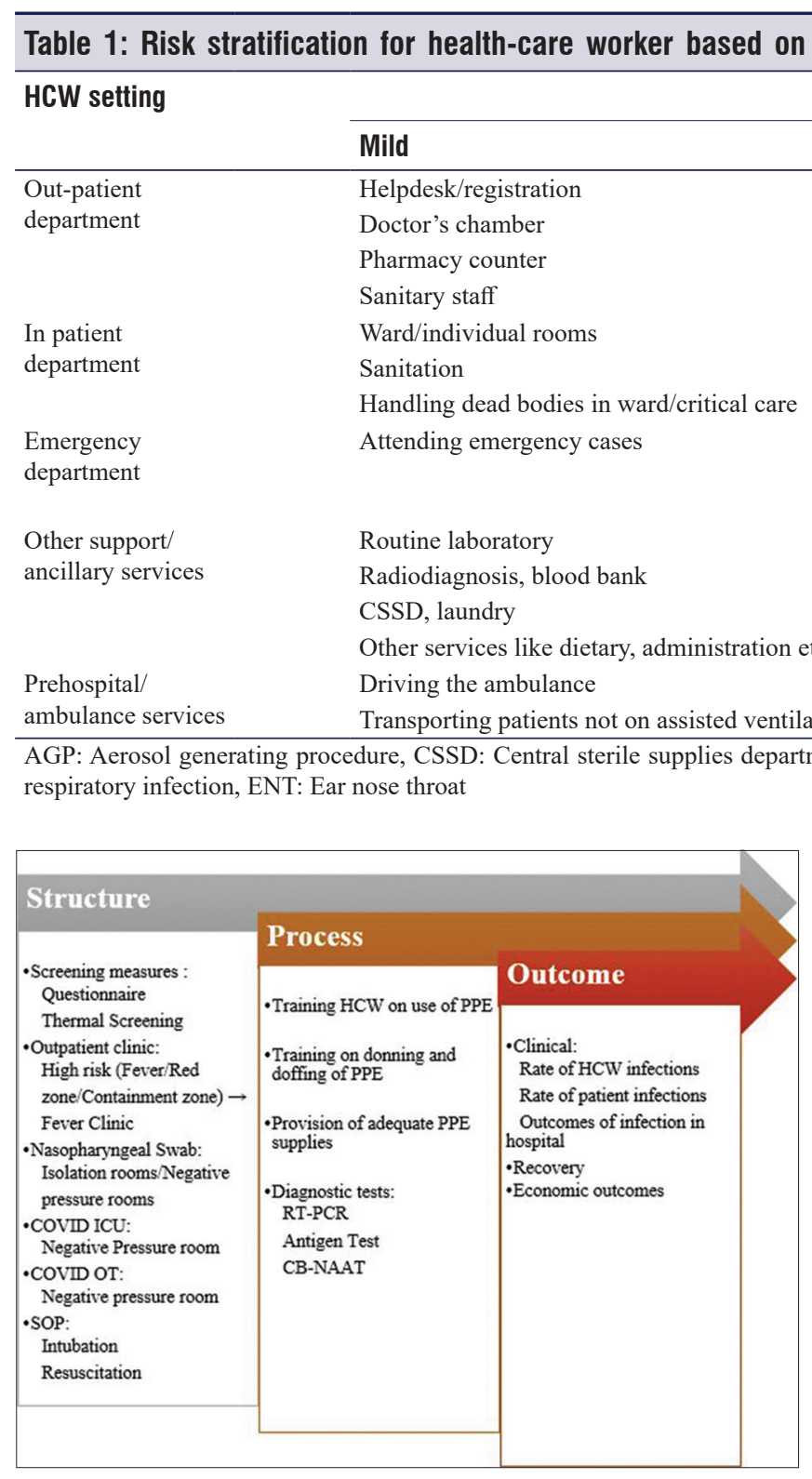

Figure 1: Donabedian model of clinical governance in health care

2. Mandatory screening of staff at entry points

3. Patients screened routinely at screening centers for symptoms and travel to endemic areas. Patients testing positive are directed to the fever clinic

4. Patients with symptoms suggestive of COVID-19 are primarily tested and treated in the fever clinic.

Recommendations for personal protective equipment for health-care worker based on risk

1. Mild risk: Triple layer medical mask and gloves

2. Moderate risk: N 95 mask, gloves, goggles, and face shield in some situations.

3. High risk: N 95 masks, coverall, goggles, nitrile examination gloves, and shoe covers are required for HCWs during aerosol-generating procedures (AGP) such as intubation, extubation, manual ventilation, bronchoscopy, noninvasive ventilation (NIV), and tracheostomy.

The N-95 respirator/mask is the main stay of protection for all HCW. Ideal recommendations mandate that it is in a shape that does not collapse easily and can be worn with a full face shield. It should have a high filtration efficiency of at least $95 \%$ protection against particulate aerosols $<0.3 \mu$. The quality of the N95 mask should be compliant with international standards (NIOSH N 95 and EN149FFP2). ${ }^{[5]}$

\section{Hand Hygiene}

The Center for Disease Control (CDC) recommends hand hygiene before and after every patient contact, contact with potentially infectious material, before and after donning and doffing of personal protective equipment (PPE), and between change of gloves. Hand hygiene should be performed using alcohol-based hand sanitizer containing $60 \%-95 \%$ alcohol or with soap and water for at least $20 \mathrm{~s} .{ }^{[6]}$

The Respiratory Therapist (RT) Independent Experts Advisory Group of the WHO provide expert opinion on respiratory support technologies, clinical management of respiratory techniques, specifications of mechanical ventilators, and on improving access to medical oxygen and equipment. ${ }^{[7]}$

\section{Health-care workers at the fever clinic}

(May receive patients from a triage area/symptomatic patients) physician, nursing staff, and RT:

1. The fever clinic should be a unit with adequate ventilation or should be a negative pressure room with sufficient space for accommodating the likely greater number of individuals. It should function as a separate unit with specific entry and exit pathways to prevent patient interactions 
2. Clear guidance to the staff regarding patient assessment, management, referral, and documentation

3. Good hand hygiene before and after patient contact should be practiced

4. Meticulous attention to appropriate environmental cleaning and disinfection should be strictly implemented by all staff working in the fever clinic

5. Social distancing should also be maintained among staff at all times.

All staff should be provided with appropriate PPE as per moderate risk category. They must complete training on the standard measures for donning and doffing of the PPE and their disposal from HICC.

\section{Nasopharyngeal swab collection}

The sample collection unit should be separate and the RT assigned should be equipped with a coverall PPE kit considering the high-risk exposure. Personnel responsible for transporting the sample to the lab should be well-trained regarding secure handling practices as well as spill management policies/ procedures. The health-care worker should use a particulate respirator; at least protective as N95/FFP2 (Filtering face piece) or equivalent, in cases of sample collection done during an AGP. ${ }^{[8]}$ The recommended time frame for using the same respirator for several patients is $4 \mathrm{~h}$ maximum unless it is soiled/damaged [Figure 2].

\section{Preanesthesia evaluation clinic}

Physician (anesthesiologist), nurse, and personnel for patient transportation. This is considered a moderate risk area and PPE protection appropriate to the risk should be enforced. Temperature screening of the patient must be documented.

1. Diligent handwashing before and after examination of each patient

2. Patients must be encouraged to wear a face mask that needs to be removed only for airway examination. Airway examination should be limited to mouth opening and assessment of mentohyoid distance

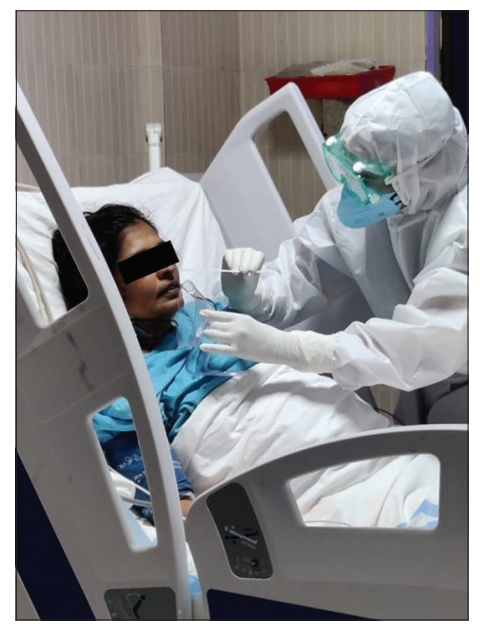

Figure 2: Nasopharyngeal swabbing by health worker in personal protective equipment
3. Stethoscopes should be disinfected with $70 \%$ isopropyl alcohol wipes

4. Gloves should be worn when documenting patient data on computers. As fomite transmission of the virus may occur, these surfaces should be disinfected periodically.

\section{Pre-COVID facility}

This unit receives patients who are at high risk for COVID and could be symptomatic and are awaiting confirmatory investigations. Patients requiring NIV should be transported to isolated rooms with negative pressure to prevent aerosol transmission of infection. Patients who deteriorate may require invasive ventilation and are transported to the COVID intensive care unit (ICU). HCWs should wear at least PPE for moderate risk category. Hand hygiene is mandatory for all the staff and care should be taken not to cross contaminate between the patients as the test result remains unclear.

\section{COVID-19 ward}

All patients who test positive but not requiring ventilatory assistance will be included here. HCWs involved are doctors (physicians, internists, anesthesiologist, and pulmonologist), nurses, and a RT as the patient can deteriorate anytime and might require respiratory support. The level of protection using a PPE could be upgraded during the performance of an AGP.

\section{COVID-19 Intensive Care Unit}

\section{Requirements in a COVID intensive care unit}

The COVID ICU should be in a separate building and away from vulnerable areas in the hospital such as neonatal, labor wards, and postsurgical ICUs. Appropriate donning and doffing areas must be provided for entry and exit from the ICUs. An ultraviolet (UV) disinfection chamber for disinfection of personal belongings such as keys and phones, alternatively alcohol-based wipes should be available. ${ }^{[9]}$

Air circulation in a COVID ICU should be through separate air handling unit (AHU). Sufficient numbers of airborne infections isolation rooms (AIIR) for AGP should be available. If single rooms are not available, then beds can be arranged with a spatial separation of at least $1 \mathrm{~m}$ away from each other. AIIR room should have fresh air exchange of 6-12/h or an airflow of $160 \mathrm{~L} / \mathrm{s}$ and should be at a negative pressure in relation to surroundings (ante room) ${ }^{[10]} \mathrm{A}$ high-efficiency particulate air filter fixed to the outlet of gases to atmosphere and for recirculation.

AGP should be performed with precautions and use of PPE commensurate with moderate-to-high risk ${ }^{[11,12]}$ with specific focus to FFP2 or FFP3 respirators. ${ }^{[13]}$ Powered air purifying respirators that use a battery-powered fan which conduct air through a filter allowing the HCWs to breathe through a mask or helmet ${ }^{[14]}$ may have a role in improving safety.

\section{Anesthesiologist in a COVID intensive care unit}

The anesthesiologist in the COVID ICU should have the privileges of monitoring patients from a remote central access 
and access to patient details on the hospital information systems to minimize the time spent in direct contact with the patient and in full PPE. A plan for interventions that include invasive lines, bronchoscopy, and intubations for the patients should be available when the anesthetists dons the PPE before entering the ICU.

There should be a minimum of 2 anesthesiologists or one anesthetist with three or more years of training along with an anesthesia technician for assistance at the time of intubation.

1. Equipment tray that is preprepared with videolaryngoscope, suction, endotracheal tube (ETT) with stylet, drugs (propofol, ketamine, etomidate, suxamethonium, rocuronium, fentanyl, midazolam, and emergency medications)

2. An elective intubation rather than unplanned emergent one is safer in adherence to HCW precautions

3. Rapid sequence intubation (RSI) is appropriate after an airway assessment and should be attempted after 3-5 min of preoxygenation when possible. If difficult airway is suspected, an additional senior anesthesiologist, videolaryngoscope, and fiberoptic scope should be ready

4. Higher than normal doses of relaxants should be used. (suxamethonium 2-2.5 mg/kg or rocuronium $1.2 \mathrm{mg} / \mathrm{kg}$ )

5. The pilot balloon should be inflated immediately after intubation with 5-7 $\mathrm{ml}$ air and a heat and moisture exchanger (HME) filter attached between the ETT and ventilator circuit and only then should ventilation be established

6. A capnometer to confirm intubation should be available

7. In the event of esophageal intubation, ventilation should be stopped, the ETT clamped and then removed. and call for additional help or use of supraglottic airway devices should be considered.

\section{Nursing in COVID intensive care unit}

1. Nurse education must include the use of PPE (donning and doffing of PPE). Mandatory use of handwashing must be insisted upon. Handwash areas should be preferably with no touch sensors. Shower areas must be provided at the doffing area

2. Education on medical waste management must be provided. Used linen should be disposed in a container with $0.5 \%$ sodium hypochlorite solution

3. Sterilize personal equipment, phones, keys, and bags either in a UV disinfection chamber or by the use of alcohol wipes

4. Protocol for assessing exposure and risk grading

5. Medical documentation must be paperless

6. Provision of remote monitoring access to minimize the entry of physicians.

Procedures posing risks to $\mathrm{HCW}$ in the COVID ICU and guidelines for protection are provided [Table 2].

In many hospitals in India, the ideal requirements for space, air exchanges, and negative pressure are not met.

1. Avoiding the use of active humidifier during conventional oxygen therapy and ensuring the correct placement of high flow nasal cannula limits aerosol generation

2. Use of double limb circuits in NIV and the use of filters in bag-valve ventilation will also reduce aerosol exposure

3. Choice of appropriate airway assist devices to minimize air contamination: Use of NIV through a helmet mask with neck cushion is better in comparison delivered through an oronasal mask

4. Use of closed suction in ventilated patients avoids disconnection and aerosol dispersion during suctioning.

The buddy system (two or more-person team) is formed among the deployed hospital staff who share responsibilities for his/her partner's safety and well-being in the context of

i. Appropriately donning and doffing of PPEs

ii. Maintaining hand hygiene

iii. Taking requisite steps on observing breach of PPEs should be followed to avoid breach in infection prevention control practices.

HCWs are advised to take shower, along with disinfection of the ears and mouth after doffing. ${ }^{[1]]}$ Extended duty hours and prolonged week work hours adversely affect the safety and health of HCWs. Overseeing the work hour schedule may prevent the possibility of infections from the work area. ${ }^{[15]}$ The standard operation procedure in case a $\mathrm{HCW}$ is exposed to COVID-19 or reports symptoms suggestive of COVID-19 should be clearly defined. It is advised to provide regular quarantine for HCWs after working in COVID-19 areas. ${ }^{[4]}$

\section{Screening for preoperative surgical patients}

All elective surgical patients are screened initially at the time of presentation by a screening questionnaire that screens their symptoms and travel history. The reverse transcriptase polymerase chain reaction test is performed 2-3 days before surgical date at the time of admission and wards allotted after test results. Attendants are reduced to one per person and allowed after antigen test confirms negativity.

\section{Requirements of the anesthesiologist/respiratory therapist in the regular operating room/intensive care unit in COVID times}

The anesthesiologist in the regular theater wears PPE as per moderate risk for exposure. Visors/goggles should be worn during AGP.

Recommendations for an anesthesiologist in the operating room. ${ }^{[16]}$

1. Practice social distancing to the extent possible and encourage the trend within the department

2. Frequent handwashing on removing gloves and after each patient contact

3. Social interactions at the dining areas and canteen should be kept minimal as most of chances for exposure happen while eating as the mask cannot be worn then 


\begin{tabular}{|c|c|}
\hline $\begin{array}{l}\text { Respiratory } \\
\text { therapy procedures }\end{array}$ & Guidelines \\
\hline Oxygen therapy & $\begin{array}{l}\text { Via nasal cannula/face mask } \\
\text { Avoid HFNC }\end{array}$ \\
\hline Aerosol drug therapy & $\begin{array}{l}\text { Use only when strongly indicated } \\
\text { Reserve the use of nebulised bronchodilators for reversible bronchoconstriction, increased airway resistance or obstruction }\end{array}$ \\
\hline Airway suctioning & Use closed suction for mechanically ventilated patients \\
\hline $\begin{array}{l}\text { Airway clearance } \\
\text { therapies }\end{array}$ & $\begin{array}{l}\text { Limit the use of airway clearance therapies to clinical need unless there is significant hypoxemia in conjunction with chest } \\
\text { imaging }\end{array}$ \\
\hline & $\begin{array}{l}\text { For nonventilated patients, recommend self -care modalities by patient to limit staff exposure to aerosols } \\
\text { For ventilated patients, consider positioning for passive drainage } \\
\text { Manage atelectasis with ventilator settings manipulation }\end{array}$ \\
\hline BVM ventilation & $\begin{array}{l}\text { Place a bacterial/viral filter in line between manual resuscitator and mask/ETT } \\
\text { Ensure proper PPE (N95/PAPR, visors/goggles, gown, gloves) }\end{array}$ \\
\hline $\begin{array}{l}\text { Endotracheal } \\
\text { intubation }\end{array}$ & $\begin{array}{l}\text { Decision making on endotracheal intubation should be taken based on patient survival and possibility of transmission of } \\
\text { infection } \\
\text { Limit the number of people in the room } \\
\text { Consider RSI to avoid manual ventilation } \\
\text { Clamp the ET tube below the adapter after ET tube insertion } \\
\text { Filters are connected between ET tube and ventilator circuits }\end{array}$ \\
\hline Bronchoscopy & $\begin{array}{l}\text { Limit the need of procedure to absolute necessity } \\
\text { Ensure proper PPE }\end{array}$ \\
\hline $\begin{array}{l}\text { Mechanical } \\
\text { ventilation }\end{array}$ & $\begin{array}{l}\text { Change circuits only when visibly soiled } \\
\text { Antibacterial/viral filter should be placed on the expiratory limb of the circuit } \\
\text { Use closed inline suction system } \\
\text { Clamp ETT with any circuit disconnection reserve patient transport for procedures and studies deemed essential for patient care }\end{array}$ \\
\hline Equipment cleaning & Ventilator cleaning and disinfection after each use as per recommended guidelines \\
\hline NIV & BIPAP or CPAP - not recommended for impending respiratory failure \\
\hline
\end{tabular}

4. RSI to avoid ventilation during mask holding. Inflation of cuff and connection to circuit with a HME filter

5. Prophylactic use of antiemetics to avoid vomiting or retching after extubation.

\section{COVID Operation Theater ${ }^{[5]}$}

As mentioned for the COVID ICU, location of the COVID operation theater (OT) is important and should be away from the main stream pathway of patient care. As the potential patients are infected, a green corridor during transit should be ensured. Gurney/bed with a plastic cover and the use of aerosol boxes to minimize aerosol dispersion during transport could be useful although concerns for decontamination exist [Figure 3].

Personnel in the COVID OT should be kept at minimum and PPE gear should be at high-risk contact requirements. A separate donning room is needed but less important than the doffing room that should have a free access from the OT and provided with a wash area and shower and proper receptacles to discard the infected gowns and equipment.

The recirculation of air through AHUs is an absolute contraindication for COVID OTs as recirculation of

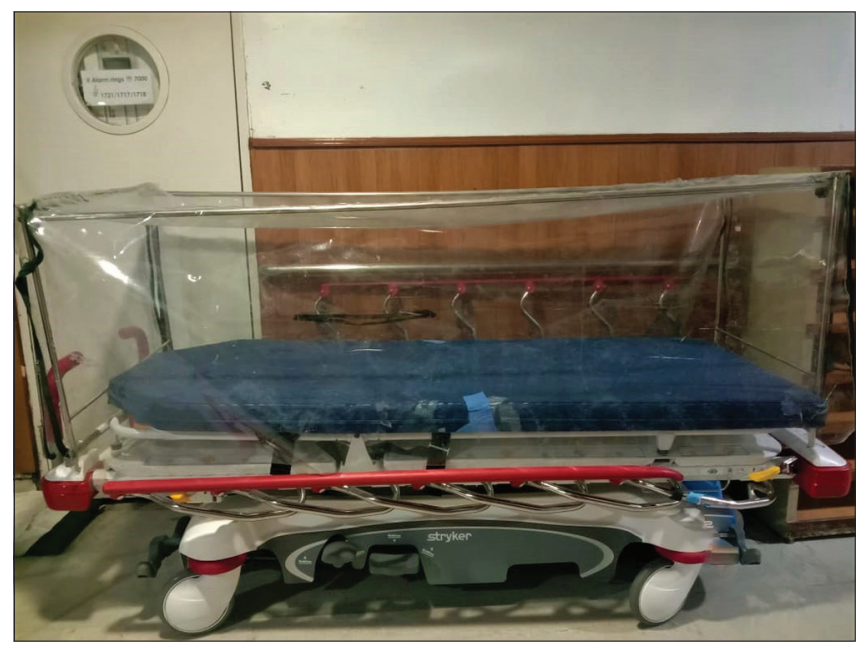

Figure 3: Gurney with enclosure

virus-laden particles from the patient must be prevented. Negatively pressured OT needs investment in time and money and may not be available readily. To prevent the free passage of COVID-infested air passing to the outside as an interim measure, the positive pressure and air conditioning system must be switched off and air return vents must be blocked. 
The AHU must receive adequate supplies of fresh noncontaminated air and an exhaust blower should carry the air from the operating room (OR), preferably treat the air and release to a nonpolluting area. The exhaust air quantity should be greater than the supply air quantity so that a negative pressure of minimum $2.5 \mathrm{~Pa}$ and preferably more $>5 \mathrm{~Pa}$ is achieved in the room. The supply air should have a minimum of 12 air changes per hour, and the extract duct should be placed above the patient's head to remove infested air efficiently. ${ }^{[5]}$

An alternative suggested is the use of two standalone split air conditioning units that take air from partially open windows and exhaust that carries the air outside. Limitations are that these systems are not guaranteed against recirculation of viruses. The extreme negative suction prevents efficient cooling of the OT and makes working conditions difficult.

Protection to the health-care workers can be enhanced by the use of transparent plastic sheets and by the aerosol box [Figure 4] to prevent dispersion of aerosols. ${ }^{[17,18]}$ The use of the aerosol box again has been controversial as it may impede the visibility and ease of intubation. There is limited scope for assistance from an assistant and has been shown to be unsafe in the management of difficult airways. Efficiency of the protection offered is also controversial as scope for spread during cleaning or disinfection and breach of PPE during its use have been documented. Concerns of decontamination after use also exist and recommendations suggest that this cannot substitute the use of good PPE for HCW. ${ }^{[19]}$

\section{Health-Care Workers for Ancillary Services}

Laboratories undertaking SARS-CoV-2 testing should adhere to the recommended biosafety practices stringently. Testing clinical samples that may probably contain SARS-CoV-2 should be performed in appropriately equipped laboratories by staff trained in the relevant technical and safety procedures. National guidelines on laboratory biosafety should be followed in all circumstances. ${ }^{[20]}$

Staff of housekeeping facility, Central Sterile Services Department, and laundry should wear the recommended PPE while disinfecting or cleaning and laundering linen from corona suspect or positive ward patients. Wear and

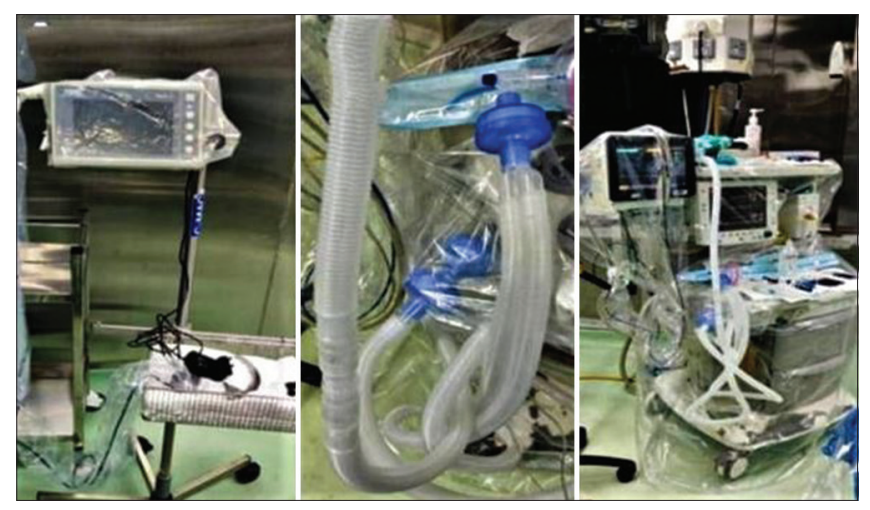

Figure 4: Equipment in theater with protection tear-resistant reusable rubber gloves can be used for safe handling and laundering of soiled linen. Staff providing care to COVID-19-positive patients need to be actively followed-up for the development of symptoms and should be provided with occupational health support.

\section{Occupational Health and Safety}

Health-care administration should ensure the security and take adequate measures to forestall all kinds of discrimination and violence against HCWs associated with COVID-19. Amidst the rapidly rising COVID 19 counts, several incidents of harassment and violence against physicians and HCWs have been reported. An ordinance has been released by the Indian government, wherein violence against HCWs is considered a nonbailable offense. ${ }^{[21]}$

1. Health workers should be briefed concerning their rights and responsibilities within the context of COVID-19 response

2. Reassigning of HCWs who are at higher risk of acquiring COVID-19 infection (preexisting comorbidities, immunocompromised, or high-risk category) to roles of having lower risk of exposure should be done

3. Access to relevant clinical updates, guidelines must be made available and proper communication with $\mathrm{HCWs}$ should be facilitated ${ }^{[22]}$

4. Psychosocial health of the workers should be monitored and provide support to those who manifest evidence of stress-related disorders

5. The HCW needs to feel recognized for his work and potential risks undertaken in the process of deliverance of health care. Adequate compensation in the form of monetary, days off, and an assurance of quality health care in the event the HCW contracts illness should be made.

\section{Conclusion}

The care to be provided to the HCW is paramount to ensure continuity in care to patients. The availability of a vaccine may provide some relief in number of infected patients and safe guarding $\mathrm{HCW}$; however, possibility of newer and more virulent strains must be recognized. Organizations need to develop a robust and sustainable model and invest resources that will ensure that systems are in place. Scope for improvements in quality should be always kept in mind and protocols altered as per the changing profile of the epidemic. Models targeting safety and physical and mental welfare of the $\mathrm{HCW}$ while preventing dissemination of the disease should be the goal for the current situation.

\section{Declaration of patient consent}

The authors certify that they have obtained all appropriate patient consent forms. In the form the patient(s) has/have given his/her/their consent for his/her/their images and other clinical information to be reported in the journal. The patients understand that their names and initials will not be published 
and due efforts will be made to conceal their identity, but anonymity cannot be guaranteed.

\section{Financial support and sponsorship}

Nil.

\section{Conflicts of interest}

There are no conflicts of interest.

\section{RefERENCES}

1. WHO Coronavirus Disease (COVID-19) Dashboard. Available from: https://covid19.who.int/. [Last accessed on $2020 \mathrm{Feb} 01]$.

2. World Health Organization. Coronavirus Disease 2019 (COVID-19) Weekly Epidemiological Report 27 January 2021. WHO; 2021. Available from: https://www.who.int/publications/m/item/weekly-epidemiologicalupdate---27-january-2021. [Last accessed on 2021 Feb 01].

3. Binder C, Torres RE, Elwell D. Use of the donabedian model as a framework for COVID-19 response at a hospital in suburban Westchester County, New York: A facility-level case report. J Emerg Nurs 2021;47:239-55.

4. Ministry of Health \& Family Welfare. Advisory for Managing Health Care Workers Working in COVID and Non-COVID Areas of the Hospital; 2020. Available from: https://www.mohfw.gov.in/pdf/ AdvisoryformanagingHealthcareworkersworkinginCOVIDandNon COVIDareasofthehospital.pdf. [Last accessed on $2021 \mathrm{Feb}$ 04].

5. Malhotra N, Bajwa SJ, Joshi M, Mehdiratta L, Trikha A. COVID operation theatre- advisory and position statement of Indian Society of Anaesthesiologists (ISA National). Indian J Anaesth 2020;64:355-62.

6. CDC. Coronavirus Disease 2019 (COVID19). Centres for Disease Control and Prevention; 2020. Available from: https://www.cdc.gov/ coronavirus/2019-ncov/hcp/hand-hygiene.html. [Last accessed on 2021 Feb 07].

7. World Health Organization. Novel Coronavirus (COVID-19) Respiratory Therapists Independent Experts Advisory Group Terms of Reference; 2020. p. 19. Available from: https://www.who.int/docs/ default-source/documents/emergencies/covid-19-respiratory-therapistsindependent-experts-advisory-group-tor.pdf?sfvrsn=ecdc2de1_2. [Last accessed on 2021 Feb 07].

8. World Health Organization. Infection Prevention and Control during Healthcare When COVID 19 Is Suspected: Interim Guidance. Geneva: WHO;2020. Available from: https://www.who.int/publications/i/ item/10665-331495. [Last accessed on 2021 Feb 04].

9. Sharma J, Nasa P, Reddy KS, Kuragayala SD, Sahi S, Gopal P, et al. infection prevention and control for ICU during COVID-19 pandemic: Position Paper of the Indian Society of Critical Care Medicine. Indian J
Crit Care Med 2020;24:S280-9.

10. World Health Organization. Natural Ventilation for Infection Control in Health-Care Settings. Geneva: WHO; 2009. Available from: https:// www.who.int/water_sanitation_health/publications/natural_ventilation/ en/. [Last accessed on $2021 \mathrm{Feb}$ 07].

11. Ferioli M, Cisternino C, Leo V, Pisani L, Palange P, Nava S. Protecting healthcare workers from SARS-CoV-2 infection: Practical indications. Eur Respir Rev 2020;29:1-10.

12. Christopher DJ, Isaac BT, Rupali P, Thangakunam B. Health-care preparedness and health-care worker protection in COVID-19 pandemic. Lung India 2020;37:238-45.

13. Personal protective equipment (PPE) needs in healthcare settings for the care of patients with suspected or confirmed novel coronavirus (2019 nCoV). Available from: https://www.ecdc.europa.eu/en/publicationsdata/personal-protective-equipment-ppe-needs-healthcare-settingscare-patients. [Last accessed on $2021 \mathrm{Feb} 04$ ].

14. Wax RS, Christian MD. Practical recommendations for critical care and anesthesiology teams caring for novel coronavirus (2019-nCoV) patients. Can J Anaesth 2020;67:568-76.

15. Weaver MD, Landrigan CP, Sullivan JP, Brien CS, Qadri S, Viyaran N, et al. The Association between Resident Physician Work-Hour Regulations and Physician Safety and Health. Am J Med 2020;133:e343-54.

16. Malhotra N, Joshi M, Datta R, Bajwa SJ, Mehdiratta L. Indian Society of Anaesthesiologists (ISA National) Advisory and Position Statement regarding COVID-19. Indian J Anaesth 2020;64:259-63.

17. Babu KC, Rajan S, Paul J, Kumar L. Anesthetic management of a COVID 19 suspected patient for mastectomy. Saudi J Anaesth 2020;14:411-2.

18. Vijayaraghavan S, Puthenveettil N. Aerosol box for protection during airway manipulation in covid-19 patients. Indian J Anaesth 2020;64:S148-9.

19. Sorbello M, Rosenblatt W, Hofmeyr R, Greif R, Urdaneta F. Aerosol boxes and barrier enclosures for airway management in COVID-19 patients: A scoping review and narrative synthesis. Br J Anaesth 2020;125:880-94.

20. Government of India, Guidelines for sharing of biological, clinical samples and data for research related to COVID- 19. India; 2020. Available from: http://www.serb.gov.in/pdfs/what-new/Guidelines $\% 20$ for $\% 20$ sharing $\% 20$ of $\% 20$ samples $\% 20$ and $\% 20$ data $\% 20$ for $\% 20$ research $\% 20$ related $\% 20$ to\%20COVID\%2019.pdf. [Last accessed on $2021 \mathrm{Feb} 07]$.

21. Covid-19: Indian government vows to protect healthcare workers from violence amid rising cases. BMJ. 2020 ;369:m1631. doi: 10.1136/bmj. m1631. PMID: 32327409.

22. World Health Organization. Health Workforce Policy and Management in the Context of the COVID-19 Pandemic Response: Interim Guidance; 2020. Available from: https://apps.who.int/iris/handle/10665/337333. [Last accessed on $2021 \mathrm{Feb} 04$ ]. 